\title{
Modal Analysis of a PMSG-Based DC Electrical Power System in the More Electric Aircraft Using Eigenvalues Sensitivity
}

\author{
Fei Gao, Xiancheng Zheng, Member, IEEE, Serhiy Bozhko, Member, IEEE, \\ Christopher Ian Hill, Member, IEEE, and Greg Asher, Fellow, IEEE
}

\begin{abstract}
This paper deals with the modeling and small signal stability analysis of a DC-distribution electrical power system (EPS) sourced by a permanent magnet synchronous generator (PMSG). The topology employed here is one of the main candidates for future more-electric aircraft (MEA). A detailed mathematical model is developed and comprehensive EPS modal analysis is performed. Eigenvalue sensitivity and participation factor are utilized in order to assess the effect of machine and control parameters, as well as system operating conditions, on EPS stability. Furthermore, this paper also presents comparative analysis of system models with and without the inclusion of system cabling. This crucial analysis shows that the tendencies in stability behavior can be significantly different with and without cabling. It is therefore shown that system simplification, by removal of cabling, can deliver remarkably misleading results. Time domain simulations are carried out to support the theoretical analysis. The comprehensive analysis presented in this paper provides EPS designers with an extremely useful methodology for the selection of appropriate EPS parameters at the early design stages.
\end{abstract}

Index Terms-Modal analysis, stability, eigenvalue sensitivity, more electric aircraft, DC power distribution.

\section{INTRODUCTION}

With increasing concern about environmental protection, the development of a "more electric" system to replace the conventional mechanical and hydraulic power for vehicles has become popular in recent years. This concept has been widely accepted in transportation including automotive, ship and aircraft power systems [1], [2] The electrical power system (EPS) is a hot topic for researchers in the more electric aircraft (MEA). Various alternative architectures are investigated in [3]. Among all the candidates, DC EPS is the most promising for the future MEA application due to several advantages such as high efficiency, reduced weight and the absence of reactive power compensation devices [4], [5].

The modal analysis method [6]-[11] including participation factor, damping ratio and oscillation frequency is an efficient tool to identify the physical nature of modes, extract the critical modes and analyse the dynamic response. It has been

This work was supported by the CleanSky JTI Project, a FP7 European Integrated Project-http: //www.cleansky.eu.

F. Gao is with the Department of Electrical and Electronic Engineering, University of Nottingham, Nottingham, NG7 2RD, U.K. (e-mail: eexfg5@nottingham.ac.uk).

$\mathrm{X}$. Zheng is with the School of Automation, Northwestern Polytechnical University, Xi'an, China. (e-mail: zxcer@sina.com).

S. Bozhko, C. Hill, and G. Asher are with the Department of Electrical and Electronic Engineering, University of Nottingham, Nottingham, NG7 2RD, U.K. (e-mail: serhiy.bozhko@nottingham.ac.uk, C.Hill@nottingham.ac.uk, greg.asher@nottingham.ac.uk). widely applied to power grids [6] and doubly-fed induction generator (DFIG) based wind power generation systems [7][11]. Participation factor analysis is beneficial for identifying the mode type and analysing the participation degree of state variables on the given eigenvalues [8], [11]. Thus, it provides an efficient tool for power system stabilizer (PSS) design [6] and controller tuning [7].

Moreover, sensitivity analysis has wide applications in power system modeling and analysis [12]-[21]. The eigensensitivity theory was introduced in [12] and was used as a small signal stability assessment tool in a turbine/governor system and PSS design. Repeat computation for the eigenvalues with varying parameters is avoided which not only predicts the movement of the dominant modes of the system but also reduces the computation burden, especially in a largescale power system. In [15], comprehensive modal analysis including participation factor and eigenvalue sensitivity analysis with respect to machine and control parameters is performed for a DFIG-based wind turbine system. In [16], the small signal stability of an EPS with increased photovoltaic (PV) generation is examined using eigenvalue sensitivity with respect to system inertia. It shows that increased $\mathrm{PV}$ and DFIG-based penetration generation may render the system unstable as the damping of the critical modes is reduced. The study of sensitivity provides useful guidance for analysis, planning, and operation of power systems. It was successfully applied for optimal tuning of control parameters [17], [18], determining locations of compensating devices, for damping improvement and stability enhancement such as capacitor compensation and FACTS devices [14].

Permanent magnet machines have been widely used in aircrafts and hybrid electric vehicles due to their high power density, high efficiency, fast dynamic response and improved reliability. Compared to a DFIG-based generation system, permanent magnet synchronous generators (PMSGs) have some unique properties such as having a constant flux linkage established by the permanent magnets. Control strategies for high speed PMSG-interfaced converters are also different. Varying machine speeds, which give rise to different generation frequencies, may impact the system stability. Transmission lines are not negligible in such microgrid structures and may influence the system dynamic and steadystate performance. Thus, their effect on stability is uncertain without systematic analysis. One cannot simply apply the results obtained from a DFIG system to the targeted PMSGbased MEA EPS. Several publications have studied the stability of the EPS in the MEA using small-signal analysis [22]-[24]. In [23], small signal stability analysis of a hybrid EPS for the MEA is presented. The effect of control 


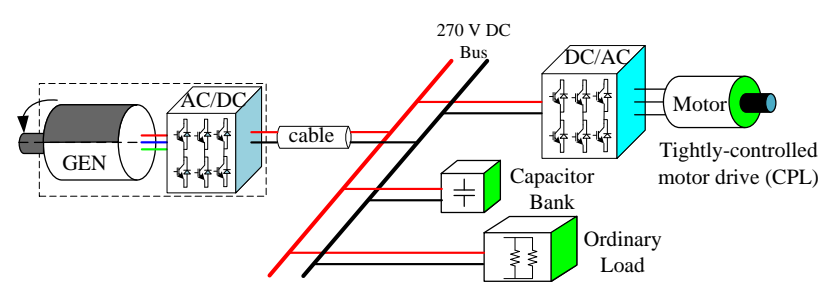

Fig. 1. Configuration of the studied system in the MEA.

bandwidth, circuit component parameters and operating conditions on stability is discussed using the eigenvalue loci. However, the eigenvalues need to be calculated repetitively with varying parameters. So far, there are few published reports dealing with comprehensive modal analysis using eigenvalue sensitivity and participation factor for the MEA EPS, especially for the potential DC EPS. A systematic analysis and design framework are required to ensure EPS stability, desired performance and robustness.

The main contributions of this paper can be summarized as follows:

(1) A nonlinear mathematical model and the corresponding linearized model for a generalized PMSG-based MEA EPS are developed.

(2) Analysis of the impact on EPS stability of the key parameters (machine parameters, cable lengths, fluxweakening and DC current controllers, as well as operating parameters such as the generator speed and the load power) has been carried out through investigation into the system eigenvalues sensitivity and corresponding participation factors.

The paper is organized as follows. Section II defines the EPS configuration and develops the corresponding mathematical model. In Section III, based on the developed model, analysis is performed which includes computation of eigenvalue sensitivities with respect to different system parameters. In order to mimic practical operation, the DC cable impedance is taken into account in this section. Section IV reassesses the influence of parameters uncertainty by ignoring the cables. Comparative eigenvalue sensitivities studies with regard to some key EPS parameters are presented. Nonlinear model time-domain simulations are performed in Section V in support of the major findings of this study. Section VI draws together the conclusions of the paper.

\section{SYSTEM Configuration AND Mathematical Model}

The representative DC-distribution MEA EPS architecture includes two main PMSGs taking power from the main engine and another PMSG driven by an auxiliary power unit (APU) [26]. Depending on the flight scenario and EPS operational regime, the system can be operated with only one active source, or with multiple sources feeding the same DC bus. A multi-generator EPS is a very complex task for eigenvalue sensitivity analysis and not possible to include in a single paper. Hence, a single PMSG-based generation EPS is investigated in this paper. The generalized EPS representation utilized in this paper is shown in Fig. 1. The PMSG provides power through an active front-end (AFE) rectifier to the main bus and loads. The on-board loads are represented by conventional resistive loads and by constant power loads

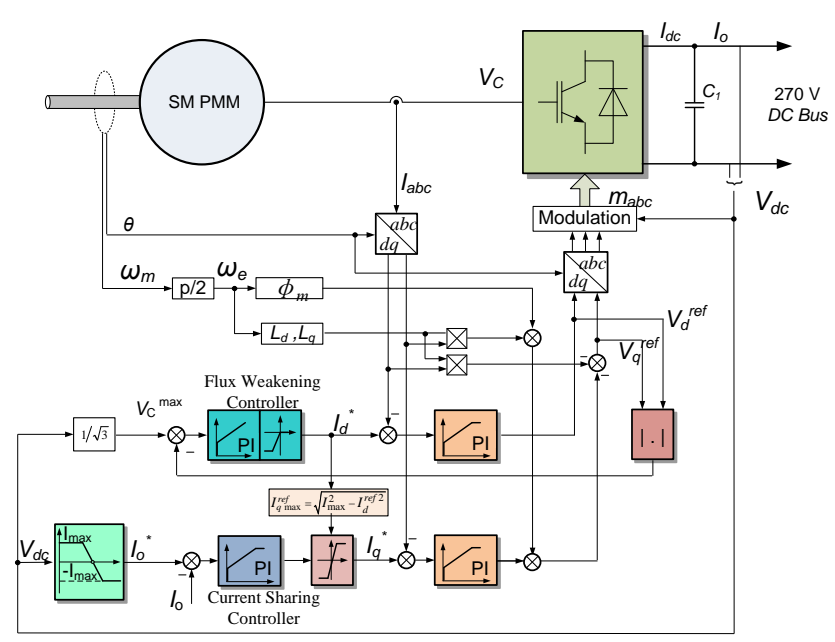

Fig. 2. Control scheme utilized in the studied system [25].

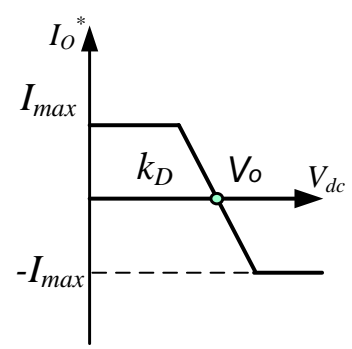

Fig. 3. Droop characteristic.

(CPL) associated with tightly controlled power-electronic converters. The capacitor bank is installed on the main $270 \mathrm{~V}$ bus. The PMSG-controlled AFE utilizes the engine mechanical power and converts it to the electric power to supply the EPS DC link. Classical vector control is used for the generator and converter to achieve decoupled control of active and reactive power [27], [28].

Fig. 2 illustrates the control scheme of the system consisting of an inner loop for current control in the $d q$ reference frame, a flux weakening controller for high speed operation of the PMSG and a DC current controller for active power regulation. To ensure appropriate current sharing between parallel modules, a droop characteristic that operates on individual modules is used. The control design process is discussed in detail in [25]. A full-order model based on this structure is developed below.

Droop control is employed in line with the I-V characteristic shown in Fig. 3. The slope of the curve in the linear section is $k_{D}$ and the reference current $\left(I_{o}{ }^{*}\right)$ is calculated corresponding to the bus voltage (input). In steady state, one can obtain the DC current reference as follows,

$$
I_{o i}^{*}=\left(V_{o}-V_{d c}\right) k_{D}
$$

where $V_{d c}$ is an actual DC-link voltage and $V_{o}$ is the nominal voltage for the main bus $(270 \mathrm{~V}$ in this study). A comprehensive model for the representative droop-controlled PMSG-based EPS is developed below.

\section{A. PMSG and Converter Model}

The synchronously rotating reference frame has been widely used to model the PMSG [27], [28]. The converter is also 
modelled based on this frame in this paper. The dynamic equations for PMSG in the $d q$ frame are as follows [29]:

$$
\left\{\begin{array}{c}
\frac{d i_{d}}{d t}=\frac{1}{L_{d}}\left(-v_{d}-R_{s} i_{d}+\omega_{e} L_{q} i_{q}\right) \\
\frac{d i_{q}}{d t}=\frac{1}{L_{q}}\left(-v_{q}-R_{s} i_{q}-\omega_{e} L_{d} i_{d}-\omega_{e} \varphi_{m}\right)
\end{array}\right.
$$

where $v_{d}, v_{q}: d$-axis, $q$-axis component of stator voltage; $i_{d}, i_{q}$ : $d$-axis, $q$-axis component of stator current; $L_{d}, L_{q}: d$-axis, $q$ axis inductance; $R_{s}$ : stator resistance; $\varphi_{m}$ : flux linkage of permanent magnet; $\omega_{e}$ : electrical rotor angular velocity.

In this study, a surface-mounted PMSG is used, thus the machine inductances in the $d$-axis and $q$-axis are identical $\left(L_{d}\right.$ $=L_{q}=L_{S}$ ) [30]. The machine speed and torque (i.e. $q$-axis current) will define the $d$-axis current in order to limit the machine voltage by appropriate defluxing. The load power has a significant simultaneous effect on both the $q$-axis and the $d$ axis current which can be seen from (3):

$$
\left\{\begin{array}{l}
v_{c}=\sqrt{v_{d}^{2}+v_{q}^{2}} \\
i_{d c}=\frac{3}{4}\left(d_{d} i_{d}+d_{q} i_{q}\right) \\
d_{d}=\frac{v_{d}}{0.5 v_{d c i}}, \quad d_{q}=\frac{v_{q}}{0.5 v_{d c i}}
\end{array}\right.
$$

where $d_{d}, d_{q}$ are the modulation indexes in corresponding directions; $v_{c}$ is the ac side voltage of the converter; $i_{d c}$ is the output DC current flowing into the capacitor. Maximum allowable phase currents are determined by the inverter and machine ratings. Maximum voltage is dependent on the available DC-link voltage and modulation method. The voltage and current limitations can be written as follows by neglecting stator resistance and the transient terms [31].

$$
\left\{\begin{array}{l}
\omega_{e} \sqrt{\left(L_{s} i_{q}\right)^{2}+\left(L_{s} i_{d}+\varphi_{m}\right)^{2}} \leq V_{c}^{\max } \\
\sqrt{I_{d}^{2}+I_{q}^{2}} \leq I_{c}^{\max }
\end{array}\right.
$$

where $V_{c}^{\max }$ and $I_{c}^{\max }$ are the maximal phase voltage amplitude at the fundamental frequency and maximal phase current, respectively.

According to the control block diagram shown in Fig. 2, it is possible to derive equations (5) where $X_{v c i}, X_{i o i}, X_{i d i}, X_{i q i}$ are the states associated with the PI controllers for the flux weakening, DC current, and $d q$-axes current controllers, respectively:

$$
\left\{\begin{array}{l}
\dot{X}_{v c i}=V_{c}^{\max }-v_{c} \\
\dot{X}_{i o i}=i_{o}^{*}-i_{o} \\
\dot{X}_{i d i}=K_{v c i} X_{v c i}+K_{v c p} v_{c}^{\max }-K_{v c p} v_{c}-i_{d} \\
\dot{X}_{i q i}=K_{i o i} X_{i o i}+K_{i o p} i_{o}^{*}-K_{i o p} i_{o}-i_{q}
\end{array}\right.
$$

Here $i_{o}$ is the load current (out of the bus capacitor); $i_{o}{ }^{*}$ is the reference of the DC current calculated by droop; $K_{v c i}, K_{v c p}, K_{i o i}$ and $K_{\text {iop }}$ are the integral gains and proportional gains for the flux weakening controller, and DC current controller, respectively (see Appendix A).

\section{B. DC-Link Model}

The dynamics on the DC-link can be expressed as:

$$
\frac{d v_{d c}}{d t}=\frac{1}{C_{1}}\left(i_{d c}-i_{o}\right)
$$

If we ignore the impedance of the DC cable between the converter and the main DC bus, $v_{d c}$ is equal to the main bus voltage $\left(v_{b}\right)$. The nominal voltage of the main bus is $270 \mathrm{~V}$, but the acceptable steady state range is between $250 \mathrm{~V}$ and $280 \mathrm{~V}$ as defined in standard MIL-STD-704F [32]:

$$
250 \mathrm{~V} \leq V_{b} \leq 280 \mathrm{~V}
$$

\section{Load Model}

As mentioned above, the load is represented by a combination of resistive load and constant power load:

$$
P_{L}=P_{r e s}+P_{c p l}=\frac{V_{b}^{2}}{R_{r e s}}+P_{c p l}
$$

where $P_{c p l}$ and $P_{\text {res }}$ are the total power of the CPL and resistive load, respectively. Hence, one can derive:

$$
i_{o}=\frac{v_{b}}{R_{r e s}}+\frac{P_{c p l}}{v_{b}}
$$

From (2)-(9), a set of state equations to represent the entire system can be established as:

$$
\dot{X}=f(X, U)
$$

where $X$ and $U$ are the vectors with respect to the state and input variables which are defined as $X=\left[v_{d c}, i_{d}, i_{q}, X_{v c i}, X_{i o i}\right.$, $\left.X_{i d}, X_{i q}\right]^{T}$. The nonlinear system equations are linearized around the equilibrium point to obtain a set of linearized dynamic equations. They can be formulated in state-space as follows:

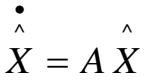

The derived system matrix $\mathrm{A}$ is too large and awkward to present here. In many practical cases the DC cable impedances cannot be neglected, especially in low voltage DC power networks. The simplified schematic for the system with cable included is depicted in Fig. 4. Since the parasitic capacitance is much smaller than the bus capacitance $\left(C_{b}\right)$ and the local capacitance $\left(C_{l}\right)$, the cabling is represented by series $R_{C}-L_{C}$ branch in this section. Two more state variables (the line current $i_{L c}$ and bus voltage $v_{b}$ ) are added to the entire system; the corresponding equations can be derived as follows: 


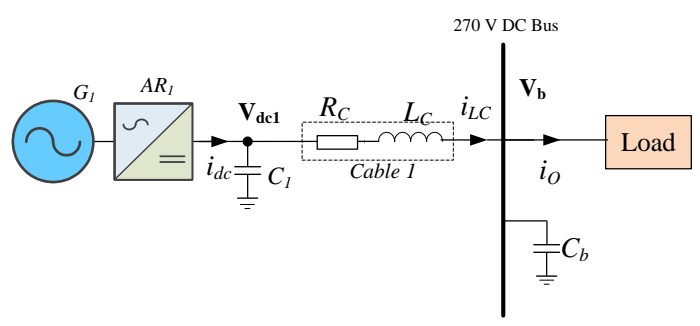

Fig. 4. Configuration of the studied system with cabling included.

$$
\left\{\begin{array}{l}
\frac{d i_{L c}}{d t}=\frac{1}{L_{c}}\left(v_{d c 1}-R_{c} i_{L c}-v_{b}\right) \\
\frac{d v_{b}}{d t}=\frac{1}{C_{b}}\left(i_{L c}-i_{o}\right)
\end{array}\right.
$$

where $v_{d c l}$ and $v_{b}$ are the voltage across the local capacitor and bus capacitor, respectively.

The whole system becomes $9^{\text {th }}$-order and it can be formulated as in (13);

$$
\dot{\hat{X}}_{C}=A_{C} \hat{X}_{C}
$$

where the entire system matrix $\boldsymbol{A}_{\boldsymbol{C}}$ is shown in Appendix B. $X_{C}=\left[v_{d c 1}, v_{b}, i_{L c}, i_{d}, i_{q}, X_{v c i}, X_{i o i}, X_{i d}, X_{i q}\right]^{T}$.

\section{Modal ANALYSIS-Single Machine System}

In practice, the system parameters such as generator inductance and resistance, control system parameters and operating conditions (machine speed, load power, etc) vary during operation. Any such change affects the system eigenvalues. In order to estimate the eigenvalue change tendency without calculating the eigenvalues repetitively, a sensitivity analysis should be undertaken. This section deals with a comprehensive modal analysis including participation factor and eigenvalue sensitivity.

Eigenvalues calculated from the state matrix may be real or complex. The complex eigenvalues can be expressed in conjugate pairs as follows:

$$
\lambda_{i}=-\sigma_{i} \pm j \beta_{i}
$$

The damping ratio and oscillation frequency corresponding to mode $\lambda_{i}$ can be defined as:

$$
\xi_{i}=\frac{\sigma_{i}}{\sqrt{\sigma_{i}^{2}+\beta_{i}^{2}}}, f_{\text {osci }}=\frac{\left|\beta_{i}\right|}{2 \pi}
$$

Participation factor analysis aids in the identification of how each state variable affects a given mode. It is a measure of the relative participation of the $k^{\text {th }}$ state variable in $i^{\text {th }}$ mode. It can be computed from the eigenvector matrices as follows:

$$
p_{k i}=\frac{\left|w_{k i} \| v_{i k}\right|}{\sum_{k=1}^{n}\left|w_{k i} \| v_{i k}\right|}
$$

where $w_{k i}, v_{i k}$ are the $k^{\text {th }}$ element in the left and right eigenvector corresponding to the $i^{\text {th }}$ eigenvalue. In general, the participation degree of the $k^{\text {th }}$ variable in the $i^{\text {th }}$ mode is measured by $p_{k i}$. As discussed in [15], $p_{k i}$ can also be regarded as the sensitivity of $\lambda_{i}$ with respect to the $k^{\text {th }}$ diagonal element of state matrix [6].

Eigenvalue sensitivity is used to measure the rate and direction of the mode movement due to variations in system parameters. The eigenvalue sensitivity of a mode $\left(\lambda_{i}\right)$ with respect to an uncertain parameter $\mu$ can be calculated as follows:

$$
\frac{\partial \lambda_{i}}{\partial \mu}=\frac{w_{i}^{T}(\partial A / \partial \mu) v_{i}}{w_{i}^{T} v_{i}}
$$

where $w_{i}$ and $v_{i}$ are the left and right eigenvector corresponding to the eigenvalue $\lambda_{\mathrm{i}}$ respectively.

The nominal system parameters used in this analysis are shown in Appendix A. Table I lists the eigenvalues of the studied system and the corresponding damping ratio and oscillation frequency for each mode. The modes $\lambda_{1,2}$ are poorly damped and regarded as the dominant modes. Table II illustrates the participation factor of the state variables. It is seen that the DC state variables $\left(v_{d c l}, i_{L c}, v_{b}\right)$ exhibit substantial participations in the dominant modes, whereas the other states participate in $\lambda_{1,2}$ weakly. Cable parameters will have a direct influence on the DC state variables. This explains why the cable impedance has strong influence on the modes $\lambda_{1,2}$. The effect of cable impedance is assessed in this section together with the other aforementioned parameters.

\section{A. Effect of Cable Parameters}

It is assumed that the cable length is $5 \mathrm{~m}$. Nominal values of cable resistance and inductance are defined as $0.6 \mathrm{~m} \Omega / \mathrm{m}$ and $0.2 \mu \mathrm{H} / \mathrm{m}$ respectively. Table III lists the eigenvalue sensitivities with respect to the cable inductance and cable resistance (calculated by (17)). The $2^{\text {nd }}$ column in the table shows the standardized unit for the eigenvalue sensitivities calculation corresponding to the variable in the $1^{\text {st }}$ column. For instance, the eigenvalue sensitivities of modes $\lambda_{1,2}$ with regard to a $1 \mu \mathrm{H}$ increment of $L_{C}$ are $1569 \pm 26440 \mathrm{i}$. This value means that an increase of inductance will shift the real part of the eigenvalue in a positive direction. Therefore, cable inductance has a significant adverse impact on stability as the eigenvalues $\lambda_{1,2}$ will move towards to the right half plane (RHP) at a fast rate with increased $L_{C}$. In contrast, an increment of cable resistance is helpful for stabilizing the system as better damping is obtained and the dominant eigenvalues move further towards left. Figs. 5 and 6 illustrate the movement of the critical eigenvalues with respect to varying cable inductance and resistance. The dominant modes $\left(\lambda_{1,2}\right)$ change significantly compared to the other modes. Increasing cable inductance $\left(L_{C}\right)$ results in the system being less damped (the poles move towards the RHP). It can be clearly seen that the eigenvalue plots in Figs. 5 and 6 match the aforementioned analysis (Table III).

\section{B. Effect of Generator Parameters}

The key parameters of the PMSG considered are the synchronous inductance $\left(L_{S}\right)$, stator resistance $\left(R_{S}\right)$ and flux linkage of permanent magnet $\left(\varphi_{m}\right)$.

\section{(1) Synchronous Inductance}


TABLE I

EIGENVALUES, DAMPING RATIO AND OSCILLATION FREQUENCY OF THE STUDIED SYSTEM WITH CABLES

\begin{tabular}{|c|c|c|c|}
\hline Mode & Eigenvalue & Damping ratio & $\begin{array}{c}\text { Oscillation } \\
\text { frequency(Hz) }\end{array}$ \\
\hline$\lambda_{1,2}$ & $-193.7 \pm 52355 \mathrm{i}$ & 0 & 8333 \\
\hline$\lambda_{3,4}$ & $-5429 \pm 7719 \mathrm{i}$ & 0.58 & 1229 \\
\hline$\lambda_{5,6}$ & $-2910 \pm 4838 \mathrm{i}$ & 0.52 & 770 \\
\hline$\lambda_{7,8}$ & $-1797 \pm 1507 \mathrm{i}$ & 0.77 & 240.3 \\
\hline$\lambda_{9}$ & -1871 & 1 & 0 \\
\hline
\end{tabular}

Eigenvalue Sensitivities for Single Generator System with Cables

\begin{tabular}{|c|c|c|c|c|c|c|}
\hline Variable & Standardized unit & $\lambda_{1,2}$ & $\lambda_{3,4}$ & $\lambda_{5,6}$ & $\lambda_{7,8}$ & $\lambda_{9}$ \\
\hline$L_{C}$ & $1 \mu \mathrm{H}$ & $1569 \pm 26440 \mathrm{i}$ & $-62.9 \pm 3.75 \mathrm{i}$ & $-7.14 \pm 10.4 \mathrm{i}$ & $1.45 \pm 2.41 \mathrm{i}$ & 0.055 \\
\hline$R_{C}$ & $1 \mathrm{~m} \Omega$ & $-506.4 \pm 27.93 \mathrm{i}$ & $5.2 \pm 3.7 \mathrm{i}$ & $1.6 \pm 0.11 \mathrm{i}$ & $0.022 \pm 0.026 \mathrm{i}$ & -0.46 \\
\hline$L_{S}$ & $1 \mu \mathrm{H}$ & $-22.99 \pm 0.4 \mathrm{i}$ & $68.56 \pm 26.94 \mathrm{i}$ & $22.57 \pm 3.1 \mathrm{i}$ & $4.31 \pm 2.51 \mathrm{i}$ & 9.5 \\
\hline$R_{S}$ & $1 \mathrm{~m} \Omega$ & $-7.55 \pm 21.09 \mathrm{i}$ & $1.72 \pm 4.86 \mathrm{i}$ & $-7.8 \pm 0.31 \mathrm{i}$ & $2.47 \pm 4.64 \mathrm{i}$ & -5.4 \\
\hline$\varphi_{m}$ & $1 \mathrm{mV} / \mathrm{s} / \mathrm{rad}$ & $60.2 \pm 50.7 \mathrm{i}$ & $-10 \pm 88.6 \mathrm{i}$ & $-0.6 \pm 25.9 \mathrm{i}$ & $-25.37 \pm 1.974 \mathrm{i}$ & 19.9 \\
\hline$K_{v c p}$ & 1 & $-3280.2 \pm 8118.6 \mathrm{i}$ & $8400.54 \pm 447.1 \mathrm{i}$ & $-330.99 \pm 605.52 \mathrm{i}$ & $1379.84 \pm 922.2 \mathrm{i}$ & -1614.22 \\
\hline$K_{v c i}$ & 1 & $-0.05 \pm 0.02 \mathrm{i}$ & $-0.13 \pm 0.56 \mathrm{i}$ & $-0.24 \pm 0.09 \mathrm{i}$ & $0.11 \pm 0.14 \mathrm{i}$ & 0.14 \\
\hline$K_{i o p}$ & 1 & $20.03 \pm 5040.51 \mathrm{i}$ & $-100.83 \pm 2949.25 \mathrm{i}$ & $1549.36 \pm 3035.6 \mathrm{i}$ & $-4287.54 \pm 943.8 \mathrm{i}$ & 5637.96 \\
\hline$K_{i o i}$ & 1 & $-0.08 \pm 0.02 \mathrm{i}$ & $0.52 \pm 0.31 \mathrm{i}$ & $0.4 \pm 0.10 \mathrm{i}$ & $0.38 \pm 1.56 \mathrm{i}$ & -2.45 \\
\hline$C_{b}$ & $1 \mathrm{mF}$ & $225.44 \pm 87093 \mathrm{i}$ & $-4404.55 \pm 1887.96 \mathrm{i}$ & $-974.8 \pm 1094.77 \mathrm{i}$ & $1324.5 \pm 494.12 \mathrm{i}$ & -424 \\
\hline$P_{c p l}$ & $1 \mathrm{~W}$ & $0.01 \pm 0.06 \mathrm{i}$ & $-0.02 \pm 0.00 \mathrm{i}$ & $0.01 \pm 0.02 \mathrm{i}$ & $-0.01 \pm 0.00 \mathrm{i}$ & 0.01 \\
\hline$P_{r e s}$ & $1 \mathrm{~W}$ & $-0.03 \pm 0.06 \mathrm{i}$ & $-0.02 \pm 0.02 \mathrm{i}$ & $0.01 \pm 0.03 \mathrm{i}$ & $-0.02 \pm 0.01 \mathrm{i}$ & 0.01 \\
\hline$\omega_{e}$ & $1 \mathrm{rad} / \mathrm{s}$ & $0.2 \pm 0.26 \mathrm{i}$ & $0.06 \pm 0.02 \mathrm{i}$ & $-0.3 \pm 0.11 \mathrm{i}$ & $-0.01 \pm 0.07 \mathrm{i}$ & 0.08 \\
\hline$k_{D}$ & 1 & $-144.3 \pm 15.36 \mathrm{i}$ & $128.1 \pm 127.42 \mathrm{i}$ & $174.4 \pm 160.88 \mathrm{i}$ & $-253.5 \pm 79.64 \mathrm{i}$ & 180.57 \\
\hline
\end{tabular}

As shown in Table III, the eigenvalue sensitivities of modes $\lambda_{1,2}$ with regard to a $1 \mu \mathrm{H}$ increment of $L_{S}$ are $-22.99 \pm 0.4 \mathrm{i}$. In other words, an increase of inductance will shift the real part of the eigenvalue in a negative direction. Hence, the EPS will be better damped and its stability margin will increase.

\section{(2)Stator Resistance}

From the results shown in Table III, it can be concluded that the effect of PMSG resistance is not significant. This is because the sensitivities of all eigenvalues, with respect to $R_{S}$, are relatively small. In other words, the eigenvalues are almost identical for systems with differing $R_{S}$ values. This is due to the fact that the stator resistance is quite small and as a result the voltage drop on the stator resistor is much smaller than the coupling terms in (1). Thus, its contribution to the operating point is insignificant compared to the machine inductance.

\section{(3)Flux Linkage of Permanent Magnet}

A small increment of flux linkage will significantly compromise the damping since the dominant modes $\left(\lambda_{1,2}\right)$ will move towards left half plane (LHP). It can be inferred from (4) that a more negative $i_{d}$ is needed to keep ac side voltage $\left(V_{c}\right)$ constant, in the high speed region, if $\varphi_{m}$ is increased. It is obvious that $\varphi_{m}$ cannot be decreased arbitrarily for a manufactured machine; however this result may be useful for generator and EPS designers.

TABLE II

Participation Factors of THE StUdied System with CABLES

\begin{tabular}{|c|c|c|c|c|c|c|c|c|c|}
\hline Mode & $\hat{v}_{d c 1}$ & $\hat{v}_{b}$ & $\hat{i}_{L c}$ & $\hat{i}_{d}$ & $\hat{i}_{q}$ & $\hat{X}_{v c i}$ & $\hat{X}_{i o i}$ & $\hat{X}_{i d i}$ & $\hat{X}_{i q i}$ \\
\hline$\lambda_{1,2}$ & 0.13 & 0.34 & 0.48 & 0 & 0.03 & 0.01 & 0 & 0 & 0 \\
\hline$\lambda_{3,4}$ & 0.07 & 0.09 & 0 & 0.17 & 0.22 & 0.12 & 0.02 & 0.15 & 0.14 \\
\hline$\lambda_{5,6}$ & 0.07 & 0.06 & 0 & 0.2 & 0.23 & 0.08 & 0.03 & 0.14 & 0.19 \\
\hline$\lambda_{7,8}$ & 0.22 & 0.15 & 0 & 0.07 & 0.04 & 0.08 & 0.31 & 0.02 & 0.1 \\
\hline$\lambda_{9}$ & 0.08 & 0.05 & 0 & 0.21 & 0 & 0.33 & 0.25 & 0.08 & 0.01 \\
\hline
\end{tabular}

TABLE III 


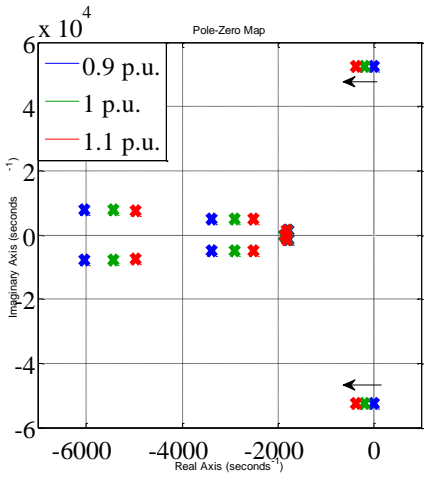

Fig. 7. Eigenvalue loci with respect to varying synchronous inductance.

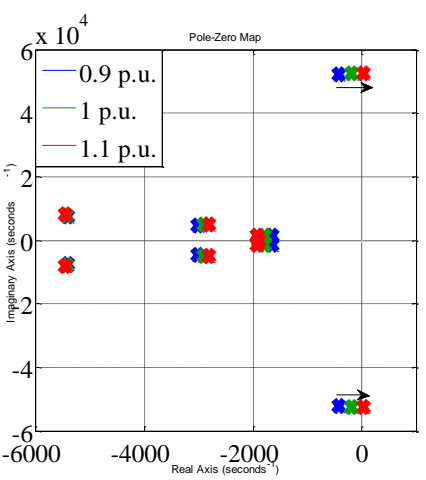

Fig. 8. Eigenvalue loci with respect to varying flux linkage of permanent magnet.

In summary, from the results in Table III, it can be concluded that the machine parametric uncertainties, or parameter variations, have a significant influence on EPS stability (except for stator resistance). The system stability margin is improved with increased machine inductance. On the other hand, a small decrease in the flux linkage of the permanent magnet is helpful for stabilizing the entire system.

The previous numeric eigenvalue sensitivity analysis is validated by the pole movement plots above. Figs. 7 and 8 show the eigenvalue plots with regard to different values of synchronous inductance and permanent magnet flux linkage respectively. It can be seen in Fig. 7 that dominant modes move to the left with increased $L_{S}$. On the contrary, the critical eigenvalues move into the RHP if the flux linkage of permanent magnet is increased. The eigenvalue plots therefore match the previously detailed analysis (Table III). This demonstrates the feasibility and efficacy of eigenvalue sensitivity analysis. The pole movement with respect to stator resistance variation is shown in Fig. 9. The movement rate is much slower compared to the pole movement shown in Figs. 7 and 8. Again, this therefore agrees with the values listed in Table III.

\section{Effect of Control Parameters}

Due to the required fast dynamic response of the entire system, the inner current loops $\left(i_{d}, i_{q}\right.$ loops $)$ are designed with a $1 \mathrm{kHz}$ bandwidth and a 0.707 damping factor. Thus, the analysis in this paper is focused on flux-weakening control and DC current control. The corresponding control parameters are

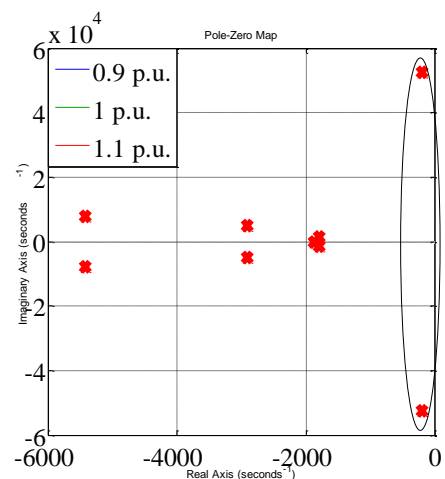

(a)

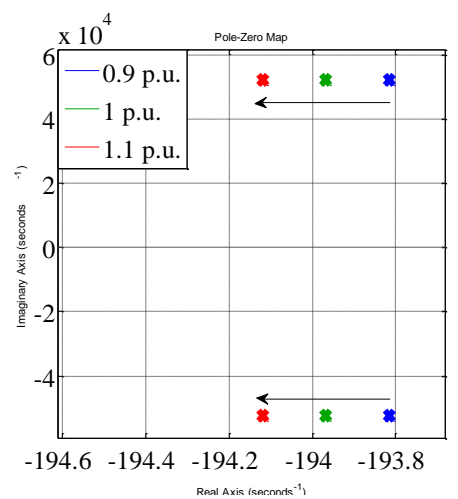

(b)

Fig. 9. Eigenvalue loci with respect to varying stator resistances. (a) Overview. (b) Zoomed area of dominant poles.

given in Appendix A. Table III displays the eigenvalue sensitivities with regard to the proportional gain and integral gain of the field weakening controller $\left(K_{v c p}, K_{v c i}\right)$ and the DC current controller $\left(K_{i o p}, K_{i o i}\right)$. A small increment in the proportional gain of the flux weakening controller $K_{v c p}$ (within a limited range) leads to $\lambda_{1,2}$ shifting to the left. However, the increase of $K_{v c p}$ is limited by $\lambda_{3,4}$ moving towards right semiplane which will lead to instability. In the case of the DC current controller, the dominant modes will move towards RHP with increased $K_{i o p}$. Overall, it can be concluded that the proportional gains of the flux weakening and current sharing controllers have a significant impact on system stability.

\section{Effect of Output Bus Capacitance}

In line with practical MEA EPS, the local capacitor $\left(C_{l}\right)$ is fixed to $1 \mathrm{mF}$. The eigenvalue sensitivity with regard to bus capacitance $\left(C_{b}\right)$ can be seen from Table IV. Critical eigenvalues will move to the left when $C_{b}$ is increased from $0.2 \mathrm{mF}$ to $0.4 \mathrm{mF}$ and then move to the right (towards the RHP) when $C_{b}$ is more than $0.4 \mathrm{mF}$. In other words, beyond a certain bus capacitance, an increased $C_{b}$ will decrease the damping due to the dominant modes.

Thus, the system stability cannot be improved by simply increasing $C_{b}$. As the eigenvalue sensitivities, with respect to 2 $\mathrm{mF}$ or $3 \mathrm{mF} C_{b}$, are reduced compared to the case of $1 \mathrm{mF} C_{b}$, it can be inferred that all the modes including the critical modes will gradually converge to a single point in the s-plane. 
TABLE IV

First-Order Eigenvalue Sensitivities With DifFERent Bus CaPacitances

\begin{tabular}{|c|c|c|c|c|c|}
\hline$C_{b}$ & $\lambda_{1,2}$ & $\lambda_{3,4}$ & $\lambda_{5,6}$ & $\lambda_{7,8}$ & $\lambda_{9}$ \\
\hline $0.2 \mathrm{mF}$ & $-5358 \pm 164500 \mathrm{i}$ & $-3714 \pm 1258 \mathrm{i}$ & $-1545 \pm 1411 \mathrm{i}$ & $1585 \pm 630.8 \mathrm{i}$ & -319.2 \\
\hline $0.3 \mathrm{mF}$ & $-736.5 \pm 86530 \mathrm{i}$ & $-3211 \pm 1468 \mathrm{i}$ & $-1520 \pm 914.5 \mathrm{i}$ & $1574 \pm 382.6 \mathrm{i}$ & -296.7 \\
\hline $0.4 \mathrm{mF}$ & $657.7 \pm 5434 \mathrm{i}$ & $-2813 \pm 1601 \mathrm{i}$ & $-1470 \pm 498.3 \mathrm{i}$ & $1488 \pm 153 \mathrm{i}$ & -270.8 \\
\hline $1 \mathrm{mF}$ & $1148 \pm 11390 \mathrm{i}$ & $-1567 \pm 1609 \mathrm{i}$ & $-564.8 \pm 382.9 \mathrm{i}$ & $688 \pm 294.5 \mathrm{i}$ & -135.5 \\
\hline $2 \mathrm{mF}$ & $548.5 \pm 3155 \mathrm{i}$ & $-804.8 \pm 951.6 \mathrm{i}$ & $-50.1 \pm 198 \mathrm{i}$ & $240.8 \pm 205.4 \mathrm{i}$ & -50.7 \\
\hline $3 \mathrm{mF}$ & $299.7 \pm 1443 \mathrm{i}$ & $-447.9 \pm 596 \mathrm{i}$ & $0.4 \pm 85.7 \mathrm{i}$ & $120.1 \pm 137.6 \mathrm{i}$ & -25.4 \\
\hline
\end{tabular}

\section{E. Effect of Operating Conditions}

Load power and generator speed are the main concern when considering EPS operating conditions. It can be seen in Table III that higher speed operation deteriorates the system stability as $\lambda_{1,2}$ and $\lambda_{3,4}$ move towards the RHP with increase of machine speed. The less damped modes, $\lambda_{1,2}$, will also approach the RHP if load power is increased. This is therefore a good match with the well-known CPL property that negative incremental impedance compromises system stability [33], [34].

\section{MODAl ANALYSIS WiTHOUT CABLES}

In many cases, cables are neglected in the modelling process in order to simplify the analytical result. However, this section will show that this may lead to inaccurate, and sometimes even incorrect, outcomes and conclusions. Here the system model without cabling is reassessed using the same procedure detailed previously. Based on the matrix in (13), eigenvalues, the relevant damping ratios and the oscillation frequencies for this case are shown in Table V. In addition, Table VI illustrates the new participation factors. It can be seen that modes $\lambda_{1,2}$ are the least damped modes (see Table V) and they are mainly associated with the DC link voltage and $q$ axis current. $\lambda_{3,4}$ are more associated with the $d$-axis current and $\lambda_{7}$ is mainly related to flux-weakening controller and DC current controller.

Table VII lists the eigenvalues sensitivities for the system without cables. It can be observed that the influences of some parameters on stability are the opposite of those found previously with cabling included, as will be discussed below.

\section{A. Effect of Generator Parameters}

In contrast to the system with cables included, the real part of the eigenvalue sensitivity of mode $\lambda_{1,2}$, with regard to the machine inductance $\left(L_{S}\right)$, is now positive. Hence the system stability degrades with an increase in stator inductance. As for the flux linkage, an increment of $\varphi_{m}$ will now shift the eigenvalues to the left. This is again opposite to the conclusion drawn from Table III.

\section{B. Effect of Control Parameters}

It shows in Table VII that the critical modes $\lambda_{1,2}$ will move dramatically to the imaginary axis with a small increment of $K_{v c p}$. In other words, a small increment in proportional gain for flux-weakening controller will lead to instability. This is opposite to the cabled case in which a small $K_{v c p}$ can stabilize the system (shown in Table III).

\section{Effect of Operating Conditions}

As the machine speed mainly affects the $d$-axis current when the generator is operating in the flux-weakening region, $\lambda_{3,4}$ are the dominant modes related to the machine speed. It can be seen that the participation factor of $i_{d}$ in modes $\lambda_{3,4}$ is the largest one among all the modes. Although increased machine speed renders less damping for $\lambda_{3,4}$, the damping of the critical modes $\lambda_{1,2}$ is increased. Overall, it can be found that the increment of the speed is beneficial for reinforcing the damping of the entire system. Again this is opposite to the previous findings in Table III.

\section{Simulation STUdies}

As discussed in [22], functional models are well suited to tasks such as the investigation of EPS stability. Therefore, in support of the analysis in the previous sections, time domain simulations are presented in this section which utilize nonswitching functional models of the EPS shown in Fig. 1. The simulation scenario assumes that the load power (CPL) increases step-wise every $0.01 \mathrm{~s}$ as detailed in Appendix C. Simulation studies have been carried out for single generator systems with cables and without cables.

\section{A. Single Generator System without Cables}

First, simulations are carried out to test the system without cabling included. Results with respect to the effect of the stator inductance $\left(L_{S}\right)$ and permanent magnet flux linkage $\left(\varphi_{m}\right)$ on stability are shown in Figs. 10 and 11. $L_{S}$ is $99 \mu$ H p.u. and $\varphi_{m}$ is $0.03644 \mathrm{~V}^{*} \mathrm{~s} / \mathrm{rad}$ p.u. (See Appendix A). It can be seen from Fig. 10 that if $L_{S}$ is increased to 1.1 p.u. instability occurs when the load power exceeds $40 \mathrm{~kW}$. However, under the same test, the system is stable with $L_{S}$ set at 0.9 p.u.

Fig. 11 shows the results for variation of the permanent magnet flux linkage. It can be seen that at 0.9 p.u. the system becomes unstable under high load power $(30 \mathrm{~kW})$ whilst at 1.1 p.u. the system remains stable.

Fig. 12(a) and (b) show the dynamic responses obtained when varying the proportional gains of the flux-weakening and DC current controllers. As expected from the previously detailed analytical analysis, it shows that the EPS is very sensitive to variations in the proportional gain of the fluxweakening controller, $K_{v c p}$. After $t=0.12 \mathrm{~s}$, instability is observed if $K_{v c p}$ is increased from 0 to 3. From Fig. 12(b) it can be seen that the system becomes unstable when $K_{\text {iop }}$ is changed from 0.4 to 0.8 at $t=0.14 \mathrm{~s}$. 
TABLE V

EigenValues of THE StUdied System Without CABLeS

\begin{tabular}{|c|c|c|c|}
\hline Mode & Eigenvalue & $\begin{array}{c}\text { Damping } \\
\text { ratio }\end{array}$ & $\begin{array}{c}\text { Oscillation frequency } \\
(\mathrm{Hz})\end{array}$ \\
\hline$\lambda_{1,2}$ & $-1765 \pm 10836 \mathrm{i}$ & 0.16 & 1724 \\
\hline$\lambda_{3,4}$ & $-2823 \pm 6034 \mathrm{i}$ & 0.42 & 960 \\
\hline$\lambda_{5,6}$ & $-3034 \pm 660 \mathrm{i}$ & 0.98 & 105 \\
\hline$\lambda_{7}$ & -1556 & 1 & 0 \\
\hline
\end{tabular}

TABLE VI

Participation Factors of the StUdied System Without CABles

\begin{tabular}{|c|c|c|c|c|c|c|c|}
\hline Mode & $\hat{v}_{d c}$ & $\hat{i}_{d}$ & $\hat{i}_{q}$ & $\hat{X}_{v c i}$ & $\hat{X}_{i o i}$ & $\hat{X}_{i d i}$ & $\hat{X}_{i q i}$ \\
\hline$\lambda_{1,2}$ & 0.27 & 0.09 & 0.31 & 0.1 & 0.04 & 0.05 & 0.13 \\
\hline$\lambda_{3,4}$ & 0.05 & 0.38 & 0.06 & 0.18 & 0.01 & 0.24 & 0.08 \\
\hline$\lambda_{5,6}$ & 0.17 & 0.02 & 0.07 & 0.13 & 0.18 & 0.17 & 0.25 \\
\hline$\lambda_{7}$ & 0.08 & 0.1 & 0 & 0.1 & 0.7 & 0.02 & 0 \\
\hline
\end{tabular}

TABLE VII

First-Order Eigenvalue Sensitivities for Single Generator System Without Cables

\begin{tabular}{|c|c|c|c|cc|}
\hline Variable & Standardized unit & $\lambda_{1,2}$ & $\lambda_{3,4}$ & $\lambda_{5,6}$ & $\lambda_{7}$ \\
\hline$L_{S}$ & $1 \mu \mathrm{H}$ & $70.4 \pm 64.85 \mathrm{i}$ & $-6.84 \pm 12 \mathrm{i}$ & $12.66 \pm 4.66 \mathrm{i}$ & 1.16 \\
\hline$R_{S}$ & $1 \mathrm{~m} \Omega$ & $14.73 \pm 9.85 \mathrm{i}$ & $-12.2 \pm 0.4 \mathrm{i}$ & $1.65 \pm 5.51 \mathrm{i}$ & -3.67 \\
\hline$\varphi_{m}$ & $1 \mathrm{mV}$ s/rad & $-33.68 \pm 200.73 \mathrm{i}$ & $27.03 \pm 67.7 \mathrm{i}$ & $-11.67 \pm 9.21 \mathrm{i}$ & 10.84 \\
\hline$K_{v c p}$ & 1 & $12070.87 \pm 1852.17 \mathrm{i}$ & $-178.46 \pm 2411.1 \mathrm{i}$ & $988.34 \pm 543.24 \mathrm{i}$ & -1079.1 \\
\hline$K_{v c i}$ & 1 & $0.07 \pm 0.58 \mathrm{i}$ & $-0.46 \pm 0.11 \mathrm{i}$ & $0.1 \pm 0.05 \mathrm{i}$ & 0.11 \\
\hline$K_{i o p}$ & 1 & $5076.15 \pm 6544.32 \mathrm{i}$ & $-577.36 \pm 3010.22 \mathrm{i}$ & $-2907.7 \pm 1408.3 \mathrm{i}$ & 5537 \\
\hline$K_{i o i}$ & 1 & $1.24 \pm 0.67 \mathrm{i}$ & $0.03 \pm 0.28 \mathrm{i}$ & $-0.17 \pm 1.71 \mathrm{i}$ & -2.19 \\
\hline$C_{i}$ & $1 \mathrm{mF}$ & $-1320.4 \pm 13176.1 \mathrm{i}$ & $-3589.32 \pm 1772.45 \mathrm{i}$ & $1751 \pm 543.17 \mathrm{i}$ & -658 \\
\hline$P_{c p l}$ & $1 \mathrm{~W}$ & $0.02 \pm 0.04 \mathrm{i}$ & $-0.02 \pm 0.03 \mathrm{i}$ & $0.02 \pm 0.01 \mathrm{i}$ & -0.01 \\
\hline$P_{r e s}$ & $1 \mathrm{~W}$ & $0.00 \pm 0.02 \mathrm{i}$ & $-0.01 \pm 0.03 \mathrm{i}$ & $-0.01 \pm 0.02 \mathrm{i}$ & 0.01 \\
\hline$\omega_{e}$ & $1 \mathrm{rad} / \mathrm{s}$ & $-0.27 \pm 0.75 \mathrm{i}$ & $0.18 \pm 0.19 \mathrm{i}$ & $-0.12 \pm 0.08 \mathrm{i}$ & -0.03 \\
\hline$k_{D}$ & 1 & $350 \pm 660 \mathrm{i}$ & $-89.4 \pm 2.22 \mathrm{i}$ & $-40.24 \pm 139 \mathrm{i}$ & 0.82 \\
\hline
\end{tabular}
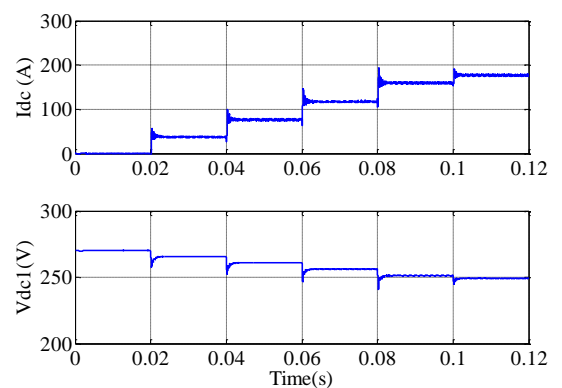

(a)
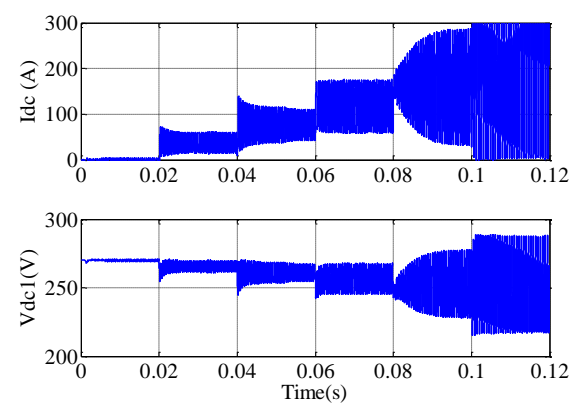

(b)

Fig. 10. Simulation results for different machine inductances. (a) $L_{S}=0.9$ p.u. (b) $L_{S}=1.1$ p.u.
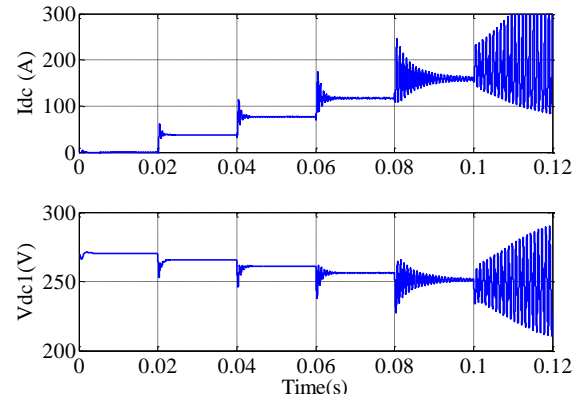

(a)
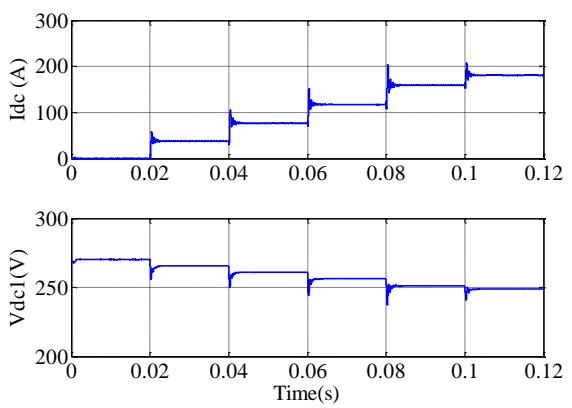

(b)

Fig. 11. Simulation results for different permanent magnet flux linkages. (a) $\varphi_{m}=0.9$ p.u. (b) $\varphi_{m}=1.1$ p.u. 

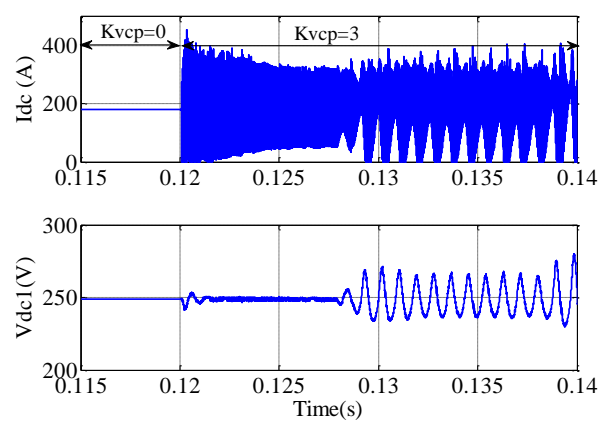

(a)
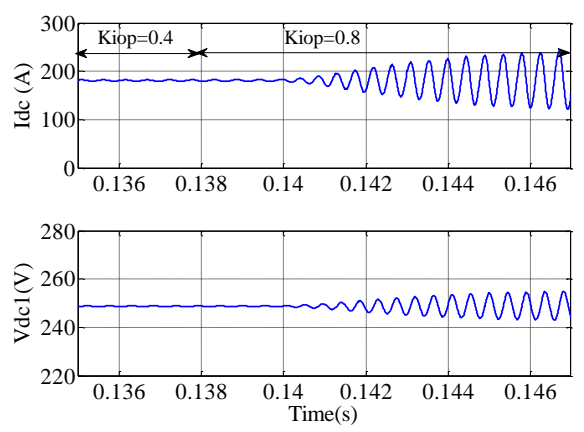

(b)

Fig. 12. Simulation results for control parameter variation. (a) $K_{v c p}$ is changed from 0 to 3 . (b) $K_{\text {iop }}$ is changed from 0.4 to 0.8 .

Fig. 13 shows the effect of generation speed on stability. In this case $0.5 \mathrm{mF}$ is used for the local capacitor $\left(C_{1}\right)$. Fig. 13(a) shows the machine speed and the stator current in both $d$ and $q$ axes. Fig. 13(b) presents the DC link current and voltage waveforms. Onset of instability can be observed in Fig. 13(a) at low generation speed $(<15 \mathrm{krpm})$, which confirms the findings in the previously detailed analytical analysis (in Section IV).

\section{B. Single Generator System with Cables}

Simulations were also performed using the single generator system shown in Fig. 4 with cabling included. Figs. 14 and 15 show the effect on the system with cabling included when generator parameters are varied. The local capacitor (at the output of the rectifier) is set to $1 \mathrm{mF}$. A small bus capacitance $(0.13 \mathrm{mF})$ is used within the system model in order to demonstrate the effect of capacitance on system behavior.

Compared to the results in Fig. 10, it can be seen in Fig. 14 that in this case, with $L_{S}$ set at $1.1 \mathrm{p} . \mathrm{u}$, the system does not exhibit instability. On the contrary, the system with 0.9 p.u. $L_{S}$ exhibits instability under high loads. This is opposite to the case without cabling included, as expected from the previous analytical analysis. Fig. 15 shows that the system with 0.9 p.u. $\varphi_{m}$ now remains stable under a high power load. However, the system with 1.1 p.u. $\varphi_{m}$ shows oscillations when the load is approaching full power after $t=0.08 \mathrm{~s}$. Again, as expected, this is opposite to the case without cabling included.

Fig. 16 shows the results for generator speed variation from $12 \mathrm{krpm}$ to $32 \mathrm{krpm}$. It can be seen that in the high speed region the whole system destabilizes. This again confirms the findings presented in Table III.

Fig. 17 confirms that the system can be stabilized at high speed by a bus capacitance $C_{b}$ of $0.5 \mathrm{mF}$. This emphasizes that
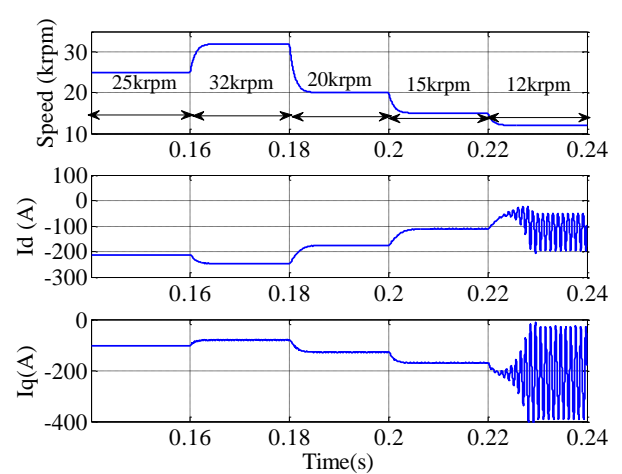

(a)
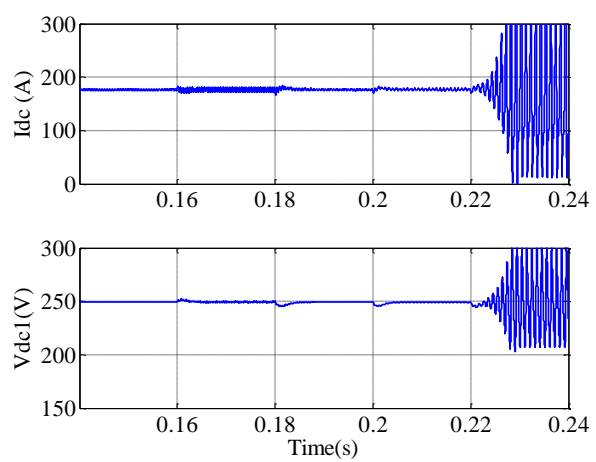

(b)

Fig. 13. Simulation results for varying machine speeds $\left(C_{b}=0.5 \mathrm{mF}\right)$. (a) Machine speed and stator current in $d q$ axes. (b) DC current and voltage.
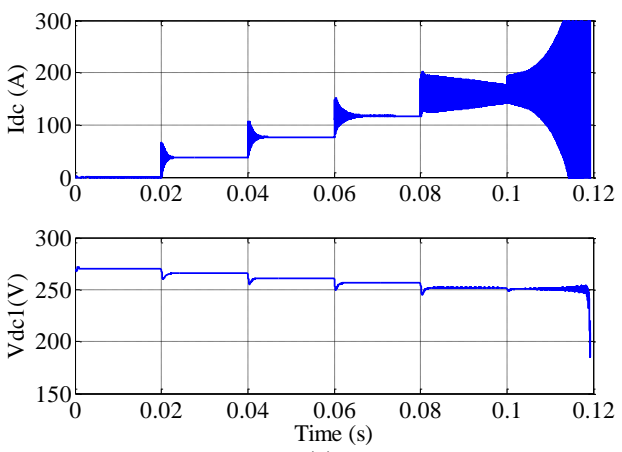

(a)
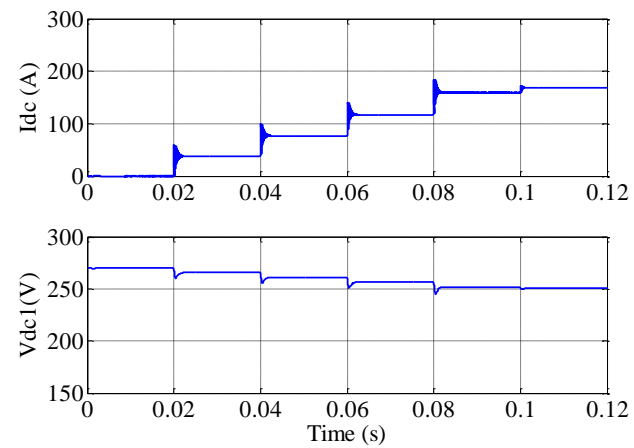

(b)

Fig. 14. Simulation results for different machine inductances. (a) $L_{S}=0.9$ p.u. (b) $L_{S}=1.1$ p.u.

an appropriate bus capacitance should be selected in order to reinforce the damping of the entire system. This is consistent with the findings in Table IV. 

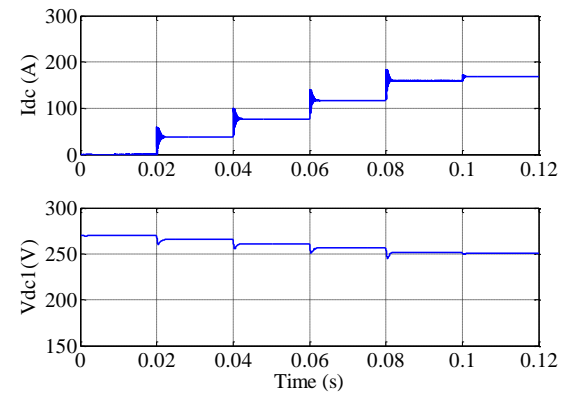

(a)
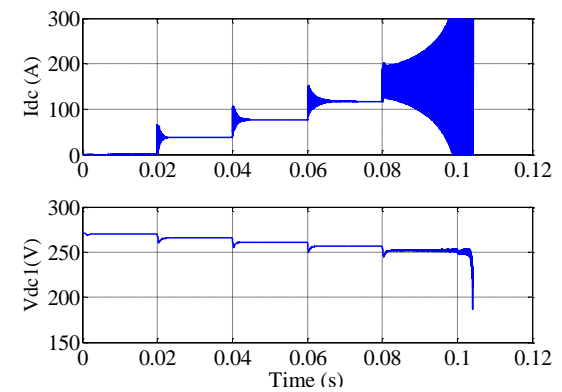

(b)

Fig. 15. Simulation results for different permanent magnet flux linkages. (a) $\varphi_{m}=0.9$ p.u. (b) $\varphi_{m}=1.1$ p.u.

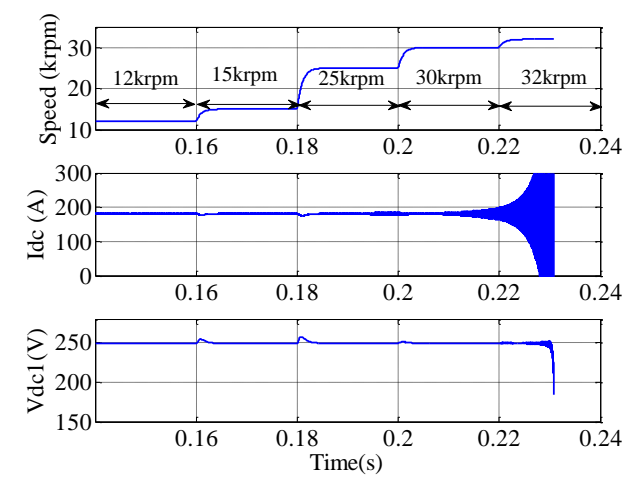

Fig. 16. Simulation results for varying machine speeds $\left(C_{b}=0.13 \mathrm{mF}\right)$.

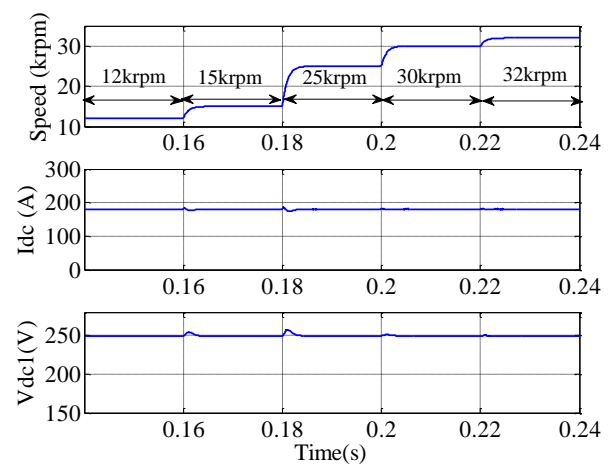

Fig. 17. Simulation results for varying machine speeds $\left(C_{b}=0.5 \mathrm{mF}\right)$.

\section{CONCLUSION}

This paper employed a DC EPS as a research objective which is a promising configuration for future MEA. A comprehensive modal analysis of a PMSG based MEA EPS has been performed. Analysis of participation factors, damping ratios and oscillation frequencies helps to understand the system characteristic. Within the analysis cable impedance was taken into consideration and the corresponding modal analysis shows that some parameters have opposite impacts on stability when cabling is ignored. The impact of parameter variation on system stability was illustrated using eigenvalue sensitivity. The applied method significantly reduces the computation burden as repetitive calculation of eigenvalues is not needed. By utilization of this technique, the effect of parameter variation on EPS behaviour, tendencies and direction of modal shift can be presented in a convenient and illustrative form. Generator parameters, control parameters and operating conditions were varied to demonstrate their effects on small signal stability. Time-domain simulations using a non-linear functional model of the example EPS have been carried out to verify analytical results.

It can be concluded that in order to obtain accurate system characteristics, cable influence cannot be neglected. Overall, the comprehensive analysis conducted in this paper offers insightful guidance for parameter optimization and system stability prediction in practical applications.

\section{APPENDIX A}

THE EPS PARAMETERS

\begin{tabular}{|c|c|c|c|}
\hline Category & Parameter & Symbol & Value \\
\hline \multirow[t]{5}{*}{ PMSG } & Machine resistance & $R_{S}$ & $1.058 \mathrm{~m} \Omega$ (1 p.u.) \\
\hline & Machine inductance & $L_{S}$ & $99 \mu \mathrm{H}$ (1 p.u.) \\
\hline & $\begin{array}{l}\text { Permanent magnet } \\
\text { flux linkage }\end{array}$ & $\varphi_{m}$ & $\begin{array}{c}0.03644 \mathrm{~V} * \mathrm{~s} / \mathrm{rad} \\
\text { (1 p.u.) }\end{array}$ \\
\hline & Number of poles & $p$ & 6 \\
\hline & Nominal power & $P_{N}$ & $45 \mathrm{~kW}$ \\
\hline \multirow[t]{3}{*}{ Cable } & Local capacitor & $C_{l}$ & $1 \mathrm{mF}$ \\
\hline & Cable resistor & $R_{C}$ & $3 \mathrm{~m} \Omega(0.6 \mathrm{~m} \Omega / \mathrm{m})$ \\
\hline & Cable inductor & $L_{C}$ & $1 \mu \mathrm{H}(0.2 \mu \mathrm{H} / \mathrm{m})$ \\
\hline Main bus & Bus Capacitor & $C_{b}$ & $0.5 \mathrm{mF}$ \\
\hline \multirow{2}{*}{$\begin{array}{l}\text { Droop } \\
\text { characteristic }\end{array}$} & Nominal voltage & $V_{o}$ & $270 \mathrm{~V}$ \\
\hline & Droop slope & $k_{D}$ & 8.5 \\
\hline \multirow{2}{*}{$\begin{array}{l}\text { Stator } \\
\text { current loop }\end{array}$} & Proportional gain & $K_{i d p}, K_{i q p}$ & 0.8785 \\
\hline & Integral gain & $K_{i d i}, K_{i q i}$ & 3908 \\
\hline \multirow{2}{*}{$\begin{array}{l}\text { Flux } \\
\text { weakening } \\
\text { control }\end{array}$} & Proportional gain & $K_{v c p}$ & 0 \\
\hline & Integral gain & $K_{v c i}$ & 5000 \\
\hline \multirow[t]{2}{*}{$\begin{array}{l}\text { DC current } \\
\text { control }\end{array}$} & Proportional gain & $K_{\text {iop }}$ & 0.4 \\
\hline & Integral gain & $K_{i o i}$ & 600 \\
\hline
\end{tabular}

APPENDIX B

StAte MAtriX $A_{C}$ OF Single Generator System 


$$
A_{C}=\left[\begin{array}{ccc}
A & F_{1} & F_{2} \\
L & -\frac{R_{c 1}}{L_{c 1}} & -\frac{1}{L_{c 1}} \\
0 & \frac{1}{C_{b}} & -\frac{1}{C_{b}} *\left(\left(\frac{2}{R_{r e s}}-\frac{P_{c p l}}{V_{b}^{2}}\right)\right)
\end{array}\right]
$$

where $L=\left[1 / L_{C l}, 0,0,0,0,0,0\right]$.

$F_{1}$ and $F_{2}$ are the column vectors consisting of control parameters and operating points.

\section{APPENDIX C}

\section{SIMULATION EVENTS FOR LOAD POWER}

\begin{tabular}{|c|c|c|c|}
\hline Time (s) & Load(kW) & Time (s) & Load(kW) \\
\hline $0-0.01$ & 0 & $0.05-0.06$ & 41 \\
\hline $0.01-0.02$ & 10 & $0.06-0.07$ & 42 \\
\hline $0.02-0.03$ & 20 & $0.07-0.08$ & 43 \\
\hline $0.03-0.04$ & 30 & $0.08-0.09$ & 44 \\
\hline $0.04-0.05$ & 40 & $0.09-0.10$ & 45 \\
\hline
\end{tabular}

\section{REFERENCES}

[1] J. A. Rosero, J. A. Ortega, E. Aldabas, and L. Romeral, "Moving towards a more electric aircraft," IEEE Aerosp. Electron. Syst. Mag., vol. 22, no. 3, pp. 3-9, Mar. 2007.

[2] J. Ciezki and R. Ashton, "Selection and stability issues associated with a navy shipboard DC zonal electric distribution system," IEEE Trans. Power Del., vol. 15, no. 2, pp. 665-669, Apr. 2000.

[3] K. Emadi and M. Ehsani, "Aircraft power systems: technology, state of the art, and future trends," IEEE Aerosp. Electron. Syst. Mag., vol. 15, no. 1, pp. 28-32, Jan. 2000.

[4] S.-M. Chen, T.-J. Liang, and K.-R. Hu, "Design, analysis, and implementation of solar power optimizer for DC distribution system," IEEE Trans. Power Electron., vol. 28, no. 4, pp. 1764-1772, Apr. 2013.

[5] P. Wheeler, and S. Bozhko, "The more electric aircraft: technology and challenges," IEEE Electri. Mag., vol. 2, no. 4, pp.6-12, Dec. 2014.

[6] L. H. Hassan, M. Moghavvemi, H. A. F. Almurib, K. M. Muttaqi, and V. G. Ganapathy, "Optimization of power system stabilizers using participation factor and genetic algorithm," Int. J. Elect. Power Energy Syst., vol. 55, pp. 668-679, Feb. 2014.

[7] Y. Mishra, S. Mishra, M. Tripathy, N. Senroy, and Z. Y. Dong, "Improving stability of a DFIG-based wind power system with tuned damping controller," IEEE Trans. Energy Convers., vol. 24, no. 3, pp. 650-660, Sep. 2009.

[8] B. Mehta, P. Bhatt, and V. Pandya, "Small signal stability analysis of power systems with DFIG based wind power penetration," Int. J. Elect. Power Energy Syst., vol. 58, pp. 64-74, Jun. 2014.

[9] F. Mei and B. Pal, "Modal analysis of grid-connected doubly-fed induction generators," IEEE Trans. Energy Convers., vol. 22, no. 3, pp. 728-736, Sep. 2007.

[10] L. Fan, C. Zhu, Z. Miao, and M. Hu, "Modal analysis of a DFIG-based wind farm interfaced with a series compensated network," IEEE Trans. Energy Convers., vol. 26, no. 4, pp. 1010-1020, Dec. 2011.

[11] D. Gautam, V. Vittal, and T. Harbour, "Impact of increased penetration of DFIG-based wind turbine generators on transient and small signal stability of power systems," IEEE Trans. Power Syst., vol. 24, no. 3, pp. 1426-1434, Aug. 2009.

[12] H. K. Nam and Y. K. Kim, "A new eigen-sensitivity theory of augmented matrix and its applications to power system stability," IEEE Trans. Power Syst., vol. 15, no. 1, pp. 363-369, Feb. 2000.

[13] K. W. Wang and C. Y. Chung, "Multi-machine eigenvalue sensitivities of power system parameters," IEEE Trans. Power Syst., vol. 15, no. 2, pp. 741-747, May 2000.
[14] L. Rouco and F. L. Pagola, "An eigenvalue sensitivity approach to location and controller design of controllable series capacitors for damping power system oscillations," IEEE Trans. Power Syst., vol. 12, no. 4, pp. 1660-1666, Nov. 1997.

[15] L. Yang, Z. Xu, J. Ostergaard, Z. Y. Dong, K. P. Wong, and X. Ma, "Oscillatory stability and eigenvalue sensitivity analysis of a DFIG wind turbine system," IEEE Trans. Energy Convers., vol. 26, no. 1, pp. 328-339, Mar. 2011.

[16] S. Eftekharnejad, V. Vittal, G. T. Heydt, B. Keel, and J. Loehr, "Small signal stability assessment of power systems with increased penetration of photovoltaic generation: a case study," IEEE Trans. Sust. Energy, vol. 4, no. 4, pp. 960-967, Oct. 2013.

[17] Y. Tang, P. Ju, H. He, C. Qin, and F. Wu, "Optimized control of DFIGbased wind generation using sensitivity analysis and particle swarm optimization," IEEE Trans. Smart Grid, vol. 4, no. 1, pp. 509-520, Mar. 2013.

[18] F. Wu, X. Zhang, K. Godfrey, and P. Ju, "Small signal stability analysis and optimal control of a wind turbine with doubly fed induction generator," IET Gener. Transm. Distrib., vol. 1, no. 5, pp. 757-760, Sep. 2007.

[19] H. A. Pulgar-Painemal and P. W. Sauer, "Towards a wind farm reduced-order model," Elec. Power Syst. Res., vol. 81, no. 8, pp. 16881695, Aug. 2011.

[20] M. Rahimi and M. Parniani, "Dynamic behavior analysis of doubly-fed induction generator wind turbines-The influence of rotor and speed controller parameters," Int. J. Elect. Power Energy Syst., vol. 32, no. 5, pp. 464-467, Jun. 2010.

[21] S. Q. Bu, W. Du, and H. F. Wang, "Probabilistic analysis of smallsignal rotor angle-voltage stability of large-scale AC-DC power systems as affected by grid-connected offshore wind generation," IEEE Trans. Power Syst., vol. 28, no. 4, pp. 3712-3719, Nov. 2013.

[22] A. Griffo and J. Wang, "Modeling and stability analysis of hybrid power systems for the more electric aircraft," Elec. Power Syst. Res., vol. 82, no. 1, pp. 59-67, Jan. 2012.

[23] K-N. Areerak, T. Wu, S. V. Bozhko, G. M. Asher, and D. W. P. Thomas, "Aircraft power system stability study including effect of voltage control and actuators dynamic," IEEE Trans. Aerosp. Electron. Syst., vol. 47, no. 4, pp. 2574-2589, Oct. 2011.

[24] K-N. Areerak, S. V. Bozhko, G. M. Asher, L. De Lillo, and D. W. P. Thomas, "Stability study of hybrid ac-dc more-electric aircraft power system," IEEE Trans. Aerosp. Electron. Syst., vol. 48, no. 1, pp. 329347, Jan. 2012.

[25] X. Zheng, F. Gao, and S. Bozhko, "Stability study of DC electric power system with paralleled generators for more-electric aircraft," in SAE 2014 Aerospace Systems and Technology Conference, Cincinnati, USA, Sep. 2014.

[26] S. Bozhko, S. Yeoh, F. Gao, and C. Hill, "Aircraft starter-generator system based on permanent-magnet machine fed by active front-end rectifier," in Proc. IECON 2014, Dallas, USA, Nov. 2014, pp. 29582964.

[27] P. C. Krause, O. Wasynczuk, and S. D. Sudhoff, "Analysis of electric machinery and drive system," Wiley-IEEE Press, 2002.

[28] W. Leonhard, "Adjustable-speed ac drives," Proc of IEEE, vol. 76, no. 4, pp. $455-471,1988$.

[29] S. Yeoh, F. Gao, S. Bozhko, and G. Asher, "Control design for PMMbased starter generator system for more electric aircraft," in Proc. $16^{\text {th }}$ EPE Conf., Lappeenranta, Finland, Aug. 2014, pp. 1-10.

[30] C. T. Pan and J. H. Liaw, "A robust field-weakening control strategy for surface-mounted permanent-magnet motor drives," IEEE Trans. Energy Convers., vol. 20, no. 4, pp. 70-709, Dec. 2005.

[31] L. Ping-Yi and L. Yen-Shin, "Voltage control technique for the extension of DC-link voltage utilization of finite-speed SPMSM drives," IEEE Trans. Ind. Electron., vol. 59, no. 9, pp. 3392-3402, Sep. 2012.

[32] Aircraft Electric Power Characteristics, Military Standard MIL-STD704F, USA, Mar. 2004.

[33] A. Emadi, A. Khaligh, C. Rivetta, and G. Williamson, "Constant power loads and negative impedance instability in automotive systems: Definition, modeling, stability, and control of power electronic converters and motor drives," IEEE Trans. Veh. Technol., vol. 55, no. 4, pp. 1112-1125, Jul. 2006.

[34] A. Rahimi and A. Emadi, "An analytical investigation of DC/DC power electronic converters with constant power loads in vehicular power systems," IEEE Trans. Veh. Technol., vol. 58, no. 6, pp.2689-2702, Jul. 2009. 